\title{
Left Atrium Size, Qualitative
}

National Cancer Institute

\section{Source}

National Cancer Institute. Left Atrium Size, Qualitative. NCI Thesaurus. Code C80423.

A descriptive adjective assigned to the quantitative measurement of the left cardiac atrium. 